of water analysis, to distill off 10c.c. at a trial, using only 100c.c. of the water to be tested, and all of these tubes have been made of the 10c.c. size, but the principle is perhaps more easily applicable tolarger tulues, because the variations of tints required would be less delicate. For very light shades I have found an amber glass with a barely perceptible olive tint to yield the best results when distended and weakened in color as described. It should be said finally, that the junction of the compound tube causes an unavoidable ringed appearance in the tube when filled with water, but with a well-made bottom to the tube there is always a clear space within the innermost circle sufficiently large to permit of comparison with the tint of the other tube.

\title{
ON THE ANALYSIS OF A SAMPLE OF MINERAL WATER FROM IRONDALE, WEST VIRGINIA.
}

\section{By A. A. Breneman.}

I have recently had occasion to examine a sample of mineral water which, as shown by the accompanying analysis, is somewhat peculiar in composition. The water was taken from a spring on the property of Mr. F. Nemegyei, at Irondale, Preston Co., West Virginia. This spring issues near the base of a hill in which beds of bituminous coal alternate with beds of fine clay, limonite and limestone. The coal in some of the veins, especially in the higher part of the hill, is very rich in pyrites.

The water has a faintly acid reaction, and in taste is weakly astringent. Its color is perceptibly yellowish in thick layers.

Analysis yields the following results expressed in grains per U. S. gallon :

Calcium Sulphate

Aluminium "

Potassium "

Magnesium "

Manganese "

Ferrous (?) "

Cobaltous "s

Sodium Chloride.

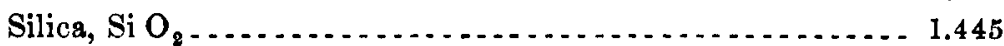

Nitric Acid 
Sulphuric acid calculated from the above corresponds to 51.003 grains $\mathrm{H}_{2} \mathrm{SO}_{4}$ per gallon; a direct determination of suiphuric acid in the same water made for the purpose of control, yielded 50.620 grains.

The composition of this water is accounted for in the main by oxidation of pyrites in the higher parts of the hill and the action of the resulting sulutions of ferrous sulphate and free acid upon the beds of fireclay, limonite and limestone through which it percolates subsequently. The comparative freedom of the water from iron is probably due to a secondary reaction taking place between weak solutions of ferrous sulphate and calcium earbonate. The abundance of the organic matter is difficult to account for from any existing evidence. This organic matter is precipitated from the water by ammonia as a reddish, floculent mass closely resembling ferric hydrate, but on drying and fusion with alkaline carbonate and nitrate it yields only an insignificant proportion of iron. This precipitate, however, contains almost the whole of the manganese present in the water. The trace of cobalt is very decided. A determination of organic matter made in another sample from the same spring taken Feb. 5, 1884, about three months later, yielded 8.257 grains per gallon. 